\title{
1 Seed germination biology of the Albany pitcher plant, Cephalotus follicularis
}

2

4

$5{ }^{1}$ Centre for Mine Site Restoration, Department of Environment and Agriculture, Curtin

Michael P. Just ${ }^{1}$, David J. Merritt ${ }^{2,3}$, Shane R. Turner ${ }^{1,2,3}$, John G. Conran ${ }^{4}$, Adam T. Cross ${ }^{1,5}$ University, GPO Box U1987, Bentley, WA 684, Australia.

${ }^{2}$ Kings Park Science, Department of Biodiversity, Conservation and Attractions, Kings Park, WA 6005, Australia.

${ }^{3}$ The University of Western Australia, School of Biological Sciences, Crawley, WA 6009, Australia

${ }^{4}$ ACEBB \& SGC, School of Biological Sciences, The University of Adelaide, SA 5005, Australia.

${ }^{5}$ Corresponding author: adam.cross@ curtin.edu.au

\section{Abstract}

Cephalotus follicularis is an ecologically unique, taxonomically isolated and range-restricted carnivorous plant that occurs exclusively within vulnerable wetland habitats in coastal southwestern Australia. Very little is known about the reproductive biology of this iconic plant species, particularly in relation to seed dormancy and the specific requirements for germination. This knowledge gap must be filled to facilitate the establishment of conservation and management initiatives for the species, as Cephalotus is increasingly impacted by habitat loss, alteration to natural hydrological and fire regimes and, in recent times, climatic change. This study aimed to determine the type of seed dormancy that the seeds of Cephalotus possess, determine the optimum conditions required for seed germination, and examine the storage behaviour of seeds. The seeds of Cephalotus are small $(1.0 \times 0.5 \mathrm{~mm})$, lightweight $(0.1 \mathrm{mg})$ and remain indehiscent within a wind-dispersed hairy achene. Results suggest that the seeds may exhibit some sensitivity to desiccation and appear to be short lived ( $<12$ months) when stored at $23{ }^{\circ} \mathrm{C}$. Maximum germination was achieved after 16 weeks incubation at $15{ }^{\circ} \mathrm{C}$ for seeds removed from the protective outer layer of the achene, while seeds retained within the protective outer layer displayed lower germination success. The post-ripening morphological changes in the embryo, limited response to gibberellic 
31 acid, and the long time period required for germination suggests that the seeds exhibit 32 morphophysiological dormancy, with a fraction of seeds remaining dormant for a period of time post-dispersal. These results highlight the importance of limiting hydrological alteration within the few remaining habitats that continue to support Cephalotus, but to ensure its long-term protection, further research focusing on phenology and in situ recruitment is required.

Keywords: Cephalotus, germination, morphophysiological seed dormancy, Albany, Southwest Australia, narrow-range endemic, Oxalidales

\section{Introduction}

The Albany pitcher plant, Cephalotus follicularis Labill., is the only species in the monotypic Cephalotaceae (Conran 2004; Cross et al. 2018c; 2019) and represents an ancient and highly isolated flowering plant lineage that arose in the Late Cretaceous (Heibl and Renner 2012). The species is both long-lived and slow growing, taking up to five years to reach reproductive maturity and develop a woody rhizome from which it resprouts following fire (Cross et al. 2019). It also exhibits remarkable ecological specificity (Cross et al. 2019), unique seedling and vegetative development (Conran and Denton 1996), and complex biotic associations with invertebrates, including an obligate mutualistic relationship with the range-restricted endemic wingless stiltlegged fly Badisis ambulans McAlpine, 1990 (Micropezidae) (Yeates 1992; Cross et al. 2019).

Cephalotus follicularis only occurs in the Southwest botanical province of Western Australia (Fig. 1), where it is endemic to a very narrow area along a coastal belt from Nannup in the west to Manypeaks in the east (Lowrie 2014; Cross et al. 2018c; 2019). It occurs predominantly in Homalospermum firmum Schauer - Callistemon glaucus Sweet peat thicket swamp fragments, where it occupies a narrow, and highly specific ecological niche along the water table (Cross et al. 2019). Although the species was more widespread in the past, its distribution is now extremely localised, predominantly due to a combination of habitat loss to agriculture, weed and stock encroachment, as well as eutrophication. Consequently, Cephalotus has undergone significant population declines in recent decades throughout its range, with fewer than $25 \%$ of the 114 recorded historical localities now remaining (Sandiford and Barrett 2010; Cross et al. 2019). 
Altered fire regimes and hydrological changes stemming from land use alteration and climatic change have also been implicated as major threatening processes (Clarke et al. 2018; Cross et al. 2019). Without urgent conservation action based on a robust understanding of the species' ecology and biology, Cephalotus faces an increasingly bleak future.

An important knowledge gap hindering the development of conservation initiatives is a poor understanding of how and when Cephalotus populations recruit from seed. Despite over two centuries of horticultural interest and botanical study of the species, its reproductive ecology has never been studied in detail and its seed germination and dormancy alleviation requirements remain poorly described. Cephalotus follicularis produce numerous achenes (unicarpellary singleseeded indehiscent fruit) which function as the diaspore (Cross et al. 2019). Achenes, despite being small and lightweight, apparently disperse poorly as populations are isolated to relatively small, disjunct wetlands and exhibit minimal genetic connectivity (Cross et al. 2019). The germination morphology of Cephalotus is also unusual, with a non-vascularised extension of the hypocotyl growing back into the achene prior to any root development (Fig. 2) (Conran and Denton 1996). Seedlings are rarely observed in natural populations (Cross et al. 2018c; Cross et al. 2019), and no studies have to date provided empirical data relating to seed ecology or germination biology in Cephalotus. Pietropaulo and Pietropaulo (1986) suggested anecdotally that cold stratification (23 months) was required to break dormancy and promote germination, and according to some authors germination may take up to a year (Pietropaulo and Pietropaulo 1986; Lecoufle 1990) and seeds often fail to germinate in cultivation unless they are removed from the enclosing protective outer layer of the achene (Lowrie 2014). However, removal of the protective outer layer is apparently not a prerequisite for germination (Conran and Denton 1996). Fire-related cues such as the smoke-derived karrikinolide $\left(\mathrm{KAR}_{1}\right)$ (Flematti et al. 2004) have been proposed as possible germination triggers for Cephalotus (Cross et al. 2018b), based upon the role of these cues in stimulating seed germination for other species from similar fire-prone habitats in southwest Western Australia (e.g., Baker et al. 2005; Cross et al. 2013; Downes et al. 2013; Cross et al. 2018b). However, there appears to be little evidence for significant post-fire seedling emergence in Cephalotus (Cross et al. 2019). Therefore, the reproductive ecology of this species needs to be understood before effective long-term conservation measures involving population maintenance, translocations, reintroductions or fire management can be developed and implemented. 
This study represents the first detailed examination of seed dormancy and germination biology undertaken for Cephalotus. As part of this study we aimed to (i) define seed dormancy type by determining seed water uptake, classifying embryo morphology, determining whether embryo growth occurs within the seed prior to germination, and examining the germination response of freshly collected seeds; (ii) determine the dormancy break and germination responses to different light and temperature cues; (iii) test the effectiveness of the naturally occurring germination stimulant $\mathrm{KAR}_{1}$; and (iv) examine the capacity of seeds to germinate following periods of desiccation and storage under different temperatures to investigate the seed storage behaviour.

102

\section{Materials and methods}

\section{Seed collection}

The seeds of Cephalotus are retained inside a small hairy achene (Fig. 2A) (Cronquist 1981; Cross et al. 2019). Mature Cephalotus achenes (brown and separating from each other) were collected from three natural populations in the Warren region of southwest Western Australia (Table 1). This region is characterised by a temperate Mediterranean coastal climate with generally cool, wet winters and warm summers (Fig. 1).

Achenes were collected in mid-late January of 2005 and 2006 (AP), 2017 (GR) and 2018 (MA) from ca. 25 individuals at each subpopulation, with collected achenes subsequently pooled from the individual plants for each population, resulting in four discrete seed accessions. After collection from AP, achenes were stored in a controlled environment room at $15{ }^{\circ} \mathrm{C}$ and $15 \%$ relative humidity prior to use in experiments. Subsequent accessions were hermetically sealed in laminated foil bags immediately following collection to prevent post-harvest drying as there was an observed decline in germination with post-harvest drying in accessions from AP. Seeds were removed from the protective layer of the achenes where required by gently rubbing achenes between rubber mats, and the seeds visually inspected to ensure the testa showed no indication of damage from the 
124

125

126

127

128

129

130

131

132

133

134

135

136

137

138

139

140

141

142

143

144

145

146

147

148

149

150

151

152

153

154

extraction process. Germination and storage experiments were implemented and conducted, where possible, within four weeks of seed collection.

TABLE 1

Achene and seed characteristics

Achene, seed and embryo characteristics were determined for seeds from GR and MA, with the larger collections from these populations allowing for the examination of some additional traits. Mass was determined for 5 and 10 replicates of 100 achenes or seeds, respectively. Seed size (measured digitally) and seed fill were determined for five replicates of 20 seeds via light microscopy (Leica DFC495 camera with analysis in Leica application X, Leica Camera, Wetzlar, Germany) and X-ray analysis (MX-20 digital X-ray cabinet, Faxitron, Tucson, USA) for all populations. Seeds were scored as filled if the endosperm was fully developed, not shrunken or retracted from the testa, and showed no signs of internal damage.

To assess water permeability of the testa in Cephalotus, three replicates of 20 filled seeds from the MA accession were placed into a Petri dish lined with filter paper irrigated with deionised (DI) water. Seeds were weighed at time 0 and then again at 1,2, 4, 8, 12, 16 and $24 \mathrm{~h}$ imbibition after being gently patted dry on paper towels before each measurement. Percentage water uptake by the seeds was determined gravimetrically, based on the fresh weight of non-imbibed seeds after subtracting the weight of the bags, with the percentage increase in seed mass calculated as:

$$
\left[\left(\mathrm{W}_{1}-\mathrm{W}_{\mathrm{d}}\right) / \mathrm{W}_{\mathrm{d}}\right] \times 100,
$$

where $\mathrm{W}_{1}$ and $\mathrm{W}_{\mathrm{d}}$ are the mass of imbibed and dry seeds, respectively (sensu Turner et al. 2009).

\section{Embryo morphology and growth}

To determine whether embryo growth occurs within Cephalotus seeds prior to emergence of the hypocotyl and, thus, if the seeds have underdeveloped embryos that grow and mature within the seed prior to germination (i.e., morphological or morphophysiological dormancy) (Baskin and 
Baskin 2014), 100 seeds were incubated for 16 weeks on water agar at $20{ }^{\circ} \mathrm{C}$ with a $12-\mathrm{h}$ photoperiod using the same approaches as outlined below for the germination trials. After this time seeds were assessed individually under a binocular microscope and 20 were selected which had signs of testa cracking and swelling (but no sign of radicle emergence or hypocotyl extension Fig. 2E $\mathrm{E}_{\mathrm{II}}$ ) which was previously noted as a precursor to imminent germination. Each of these seeds was measured longitudinally under a dissecting microscope equipped with an ocular micrometre and then dissected to remove the intact embryo, which was also measured along the same axis. Data were used to determine the embryo to seed length $(\mathrm{E}: \mathrm{S})$ ratio for each of the 20 seeds. Fresh seeds were also measured using the same approach after 24 hours hydration at $20{ }^{\circ} \mathrm{C}$ under the same conditions; however, seeds were not assessed for cracking or swelling prior to measurement or embryo extraction. The measurements from these latter seeds and embryos were used for comparative purposes.

\section{Germination biology}

To assess the germination response to temperature, light, and germination stimulants, achenes and seeds of each collection were plated in $90 \mathrm{~mm}$ Petri dishes containing $0.7 \%(\mathrm{w} / \mathrm{v})$ water agar only (control) or water agar containing $2.89 \mathrm{mM}$ gibberellic acid $\left(\mathrm{GA}_{3}\right.$; Sigma Aldrich Chemicals, Australia), or $0.67 \mu \mathrm{M}$ (AP1 and AP2) or $0.99 \mu \mathrm{M}$ (GR and MA) KAR 1 . Achenes and seeds were plated as three replicates of 15 (AP) or five replicates of 25 (GR and MA) for each treatment. Achenes are generally not produced in large quantities by Cephalotus, as subpopulations are small and individual plants rarely produce more than a few inflorescences (Cross et al. 2019), so replication was constrained by seed availability among collections. Plated achenes and seeds were placed in incubators at each of four constant temperatures: $10,15,20$ or $25^{\circ} \mathrm{C}$, either on a 12-h photoperiod, or in constant darkness (plated in darkness and wrapped in aluminum foil to exclude light) at $15^{\circ} \mathrm{C}$ for AP1 only.

Germination was defined as hypocotyl emergence to $>1 \mathrm{~mm}$, given that a non-vascularised extension of the hypocotyl emerges prior to radicle growth (Conran and Denton, 1996) (Figure $2 \mathrm{Ev}_{\mathrm{v}}$ ). Germination was scored weekly for 16 weeks in light treatments, but once only after 16 weeks in dark treatments. On completion of each experiment, all non-germinated seeds were cut- 


\section{Statistical analysis}

tested to determine viability, with seeds possessing a firm, white endosperm and embryo judged to be viable. Germination percentages are, therefore, based on the number of viable seeds.

\section{Seed storage behaviour}

To investigate the sensitivity of seeds to desiccation and to determine seed storage behaviour, freshly collected seeds (AP1) were dried at either $20 \%$ or $50 \%$ relative humidity (RH) at $15{ }^{\circ} \mathrm{C}$ for seven days. Seeds were dried to $20 \% \mathrm{RH}$ as per international standards for gene banking of orthodox seeds (FAO 2014), and drying seeds to 50\% RH allowed for examination of the potential for non-orthodox storage behaviour (i.e. desiccation sensitivity) (Hong and Ellis 1996). Following drying replicates of 15 seeds were plated on water agar as described previously. Seeds were then incubated in constant darkness at 10,15, 20 and $25^{\circ} \mathrm{C}$. Additional replicates of freshly collected seeds were dried by suspending over a non-saturated solution of lithium chloride $\left(640 \mathrm{~g} \mathrm{~L}^{-1}\right.$ or 364 $\mathrm{g} \mathrm{L}^{-1}$ to achieve $20 \%$ and $50 \% \mathrm{RH}$, respectively) (Hay et al. 2008) at $20{ }^{\circ} \mathrm{C}$, inside a $270 \times 190 \times$ $100 \mathrm{~mm}$ polycarbonate electrical enclosure box (NHP Fibox, Perth, WA, Australia) prior to being plated on water agar as described previously. Additional replicates of seeds dried under the same conditions were sealed hermetically in laminated aluminum foil bags and stored at either 23, -18 , or $-80{ }^{\circ} \mathrm{C}$ for 12 months. The bags were then retrieved and warmed at ambient temperature ( 23 ${ }^{\circ} \mathrm{C}$ ) for 24 hours, after which replicates of 15 seeds were prepared for germination testing as described previously and incubated in constant darkness at $15^{\circ} \mathrm{C}$. Germination was scored weekly after 4 weeks and the experiment concluded after 64 days. Additionally, seed viability of nongerminating seeds was tested using tetrazolium (TZ) staining. Seeds were nicked gently to allow the TZ to be absorbed into the seed, placed on filter paper saturated with $1 \%$ TZ (2,3,5-Triphenyl$2 \mathrm{H}$-tetrazolium chloride) solution and incubated for three days at $30^{\circ} \mathrm{C}$, before the embryos were extracted and analysed for staining under a binocular microscope (sensu Moore 1985). Embryos that stained a uniform red were considered viable. 
A binomial generalized linear mixed model was fitted to assess the main and interaction effects of light, temperature, $\mathrm{GA}_{3}$ and $\mathrm{KAR}_{1}$ on the outcome of seed germination success (SPSS Statistics 25, IBM, USA). Population and collection date were included as random effects. One-way ANOVA with Tukey post hoc tests were used to test the effect of incubation duration on E:S ratio for the embryo growth experiment. Preliminary analyses of all data were conducted to test the assumptions of normality (Kolmogorov-Smirnov test), linearity and homoscedasticity (Levene's test), and consequently no data transformations were required. All statistical tests were conducted using the 95\% confidence interval (CI), with significance determined by $P \leq 0.05$.

\section{Results}

\section{Achene and seed characteristics}

The diaspore in Cephalotus follicularis is a single, hairy achene with an expanded base (Fig. 2A) that is very light (achene mass $0.03 \pm 0.003 \mathrm{mg}$ ). The single, permanently enclosed seed is spindleshaped (Fig. 2B), small ( $1.0 \pm 0.07 \mathrm{~mm}$ long by $0.5 \pm 0.04 \mathrm{~mm}$ wide) and lightweight (mean seed mass $0.01 \pm 0.001 \mathrm{mg}$ ) accounting for $\sim 30 \%$ of the overall achene mass. Seed fill was high for freshly collected achenes from MA and GR (93 $\pm 3.4 \%$ and $91 \pm 4.1 \%$, respectively). Achenes were water-permeable, and seeds removed from the protective outer layer of the achene readily imbibed water, becoming ovoid in shape (Fig. 2 $\mathrm{E}_{\mathrm{II}}$ ) and increasing in mass by $56 \pm 3.9 \%$ after 24 hours, although most of the mass increase occurred within the first 2 hours of exposure to moisture.

\section{Embryo morphology and growth}

The embryo is embedded in copious granulose endosperm and is small, linear, and underdeveloped, but still possesses distinctive cotyledons (Fig. 2C). Embryo length in freshly collected, recently mature seeds from MA was $404 \pm 54.5 \mu \mathrm{m}$ (E: $\mathrm{S}=0.4 \pm 0.06)$, which increased to $772 \pm 113.5 \mu \mathrm{m}(\mathrm{E}: \mathrm{S}=0.6 \pm 0.08 ; \mathrm{F}=113.40$, d.f. $=1$, P <0.001) after 16 weeks of incubation at $20{ }^{\circ} \mathrm{C}$ (Fig. 5), just prior to radicle emergence (Fig. 2 $\mathrm{E}_{\mathrm{II}}$ ). Thus, embryo length increased by $>90 \%$ in seeds prior to germination $(\mathrm{F}=170.56$, d.f. $=1, \mathrm{P}<0.001)$. 
Germination is phanerocotylar, with emergence of the cotyledons (and seed coat remnant) from the persistent achene (Fig. 2DI-DIV) occurring after ca. 105 days on average (range 101-113). Germination was slow in all incubation temperatures, with observation of extracted seeds indicating that the first stage of germination, the emergence and expansion of the non-vascularised parenchymatous and fusiform hypocotyl extension from the seeds (Fig. 2 $\mathrm{E}_{\mathrm{III}}-\mathrm{E}_{\mathrm{V}}$ ), occurred after ca. 90 days (range 59-120 days). This was followed by the emergence of the cotyledons (Fig. 2E $\mathrm{E}_{\mathrm{VI}}$ ) and then the radicle (Fig. 2 $\left.\mathrm{E}_{\mathrm{VII}}-\mathrm{E}_{\mathrm{VIII}}\right)$. The fully-expanded cotyledons are obovate, spreading, glabrous, ca. $2 \times 0.8-1.0 \mathrm{~mm}$, and the first true leaves are alternate and non-carnivorous, followed shortly by the first carnivorous leaves (Fig. 2DIV).

\section{FIGURE 2}

The main effect of temperature on germination was highly significant (Wald $\chi^{2}=387.5$, d.f. $=3$, $P<0.001)$. Average germination probability ranged from ca. $0.2-0.8$, with significantly higher germination in seeds treated with gibberellic acid and incubated at $15^{\circ} \mathrm{C}$ (Fig. 3). No germination occurred at $5{ }^{\circ} \mathrm{C}$ in any treatment, and few germinants were observed from extracted seeds or achenes incubated at $25^{\circ} \mathrm{C}$. Although no main effect of population on germination probability was evident (Wald $\chi^{2}=1.2$, d.f. $=3, P=0.249$ ), germination probabilities were higher for seeds of 267 AP1 (Fig. S1) compared with other collections across all temperatures tested (Wald $\chi^{2}=35.6$, d.f. $268=2, P<0.001)$. This was driven predominantly by higher germination probability for AP1 in 269 control and $\mathrm{KAR}_{1}$ treatments compared with seeds from other tested populations (Fig. S1).

\section{FIGURE 3}

273 No main effect of germination stimulation treatment was evident and germination probability was 274 not improved markedly by exposure to either $\mathrm{GA}_{3}$ or $\mathrm{KAR}_{1}$ (Fig. 3). However, there was a 275 significant interaction between treatment and the removal of the protective outer layer of the 276 achene on germination probability (Wald $\chi^{2}=7.7$, d.f. $=2, P=0.021$ ), with the germination 
277 probability (across all temperatures) of seeds retained in achenes incubated on water agar 278 containing $\mathrm{KAR}_{1}$ significantly reduced compared to other treatments (Fig. 3).

279

280

Seeds removed from achenes collected from AP1 and GR did not require light to germinate at 15 ${ }^{\circ} \mathrm{C}$, nor was germination probability light-suppressed. Germination probability did not vary significantly within collections between seeds incubated on a 12-h photoperiod and seeds incubated in constant darkness and the main effect of light on germination probability was not significant (Wald $\chi^{2}=1.3$, d.f. $\left.=1, P=0.258\right)$.

285

286

287

288

289

290

291

292

293

294

295

296

297

298

299

300

301

302

303

304

305

306

307

\section{FIGURE 4}

\section{Seed storage behaviour}

Drying of seeds of AP1 to 50\% and 20\% RH for seven days markedly reduced germination probability on both water agar and water agar containing $\mathrm{GA}_{3}$, compared with freshly collected seeds (Fig. 4). Highly significant interaction effects were present between drying treatment and germination stimulation treatment (Wald $\chi^{2}=38.2$, d.f. $=2, P<0.001$ ), and between drying treatment and incubation temperature (Wald $\chi^{2}=33.9$, d.f. $=6, P<0.001$ ). Overall, drying reduced germination probability on water agar compared with fresh seeds at both at $20 \% \mathrm{RH}$ and $50 \% \mathrm{RH}$ ( $\mathrm{B}=-2.35, P<0.001$ and $\mathrm{B}=-1.55, P=0.004$, respectively), although this reduction was less pronounced for seeds incubated on water agar containing $\mathrm{GA}_{3}$ after drying at 50\% RH (Fig. 4). The amplitude of reduced germination probability for seeds dried at $50 \%$ and $20 \% \mathrm{RH}$ compared with freshly collected seeds was greatest for seeds incubated at $15^{\circ} \mathrm{C}(\mathrm{B}=0.64, P=0.261$ versus $\mathrm{B}=1.76, P=0.001)$ and $20{ }^{\circ} \mathrm{C}(\mathrm{B}=0.69, P=0.226$ versus $\mathrm{B}=1.52, P=0.004)$.

\section{FIGURE 5}

Seeds stored for 12 months at $23{ }^{\circ} \mathrm{C}$ failed to germinate (Fig. 4). Supplementary TZ staining on these seeds indicated that relatively few survived the storage period, as only $40 \%$ and $15 \%$ of embryos stained for seeds after drying at $50 \%$ and $20 \% \mathrm{RH}$ prior to storage, respectively. In contrast, around $20-40 \%$ of seeds germinated on water agar after storage for 12 months at -18 and 
$-80{ }^{\circ} \mathrm{C}$, and germination probability was not reduced significantly compared with seeds incubated on water agar alone after equilibration for 7 days at $50 \%$ and $20 \% \mathrm{RH}$ prior to storage (Fig. 4). No significant main effects for equilibration RH (Wald $\chi^{2}=0.69$, d.f. $=1, P=0.405$ ) or sub-zero storage temperature (Wald $\chi^{2}=0.20$, d.f. $=2, P=0.903$ ) on germination probability were evident, nor was there a significant interaction effect (Wald $\chi^{2}=0.45$, d.f. $=2, P=0.797$ ).

\section{Discussion}

This study provides the first empirical examination of seed dormancy type and the requirements for germination in the narrow range endemic and Gondwanan relict Cephalotus follicularis. Our data suggest that the seeds of Cephalotus possess morphophysiological dormancy (MPD) and that germination occurs within a relatively narrow thermal range $\left(15-20^{\circ} \mathrm{C}\right)$ after a long period $(8-16$ weeks) of post-dispersal embryo maturation and growth (Fig. 3) and that these processes are restricted by the presence of the protective outer layer of the achene (Fig. 3). Freshly collected seeds exhibit a degree of sensitivity to desiccation, with germinability and viability declining modestly after drying for 7 days at both $50 \%$ and $20 \%$ RH (Fig. 4). Seeds exhibited no response to the smoke-derived germination stimulant $\mathrm{KAR}_{1}$, suggesting that fire does not play a direct role in the recruitment of the species from seed.

It has been previously concluded that seed dormancy within Cephalotaceae was likely to be physiological (PD), based in part upon the lack of under-developed embryos in Poales and their under-representation within Lamiales and Oxalidales (Baskin and Baskin 2014). Germination in this present study was preceded by a period of post-dispersal embryo maturation, with significant embryo growth (i.e., a ca. 2-fold increase in embryo length prior to germination) observed after 816 weeks of incubation. This indicates that the linear embryo of Cephalotus is underdeveloped at seed maturity ( $<40 \%$ of seed length). Underdeveloped embryos can also occur in seeds with morphological dormancy (MD), but the sporadic positive response to $\mathrm{GA}_{3}$ (Figs. 3, S1), the narrow thermal germination window (Fig. 3) and the fact that germination success remained low (<50\%) for some populations even under optimal conditions (Fig. S1), suggests an additional physiological component to dormancy (Baskin and Baskin 2004; 2014). The evidence of embryo growth from the present study therefore suggests that the classification of Cephalotaceae seeds as possessing 
PD is incomplete and that the seeds of Cephalotus instead show morphophysiological dormancy (MPD), with temperature signals required to increase embryo growth potential as a precursor to embryo maturation and germination. If this is correct, then either dry after-ripening (Turner et al. 2009) or warm/cold stratification (Merritt et al. 2007b) may improve and enhance the germination of Cephalotus seeds.

Our germination data imply that the recruitment of Cephalotus under field conditions is likely to occur only within a narrow range of thermal and moisture conditions during lengthy periods of seasonal environmental stability, although after-ripening or stratification may further widen the hydrothermal range for germination. Achenes mature and disperse in late February or March (late summer to early autumn) (Cross et al. 2019), when daily temperature minima and maxima are generally between $10-15{ }^{\circ} \mathrm{C}$ and $20-23{ }^{\circ} \mathrm{C}$, respectively (Fig. 1). The achene likely enhances dispersal of seeds and precludes germination, narrowing the germination window until it is sufficiently eroded. Temperatures over the following 3-4 months of autumn and early winter appear conducive to stimulating embryo maturation and subsequent germination, as daily minimum temperatures are generally $10-15^{\circ} \mathrm{C}$ and the daily maximum rarely exceeds $20{ }^{\circ} \mathrm{C}$. Critically, rainfall during this period is usually predictable and moisture levels in the mesic habitats inhabited by Cephalotus are likely to remain high enough for an extended period to support gradual germination and seedling establishment. Indeed, Cephalotus is known to occupy a highly specific hydrological niche within occupied habitats and rarely occurs outside of drainage depressions below the seepage zone where the substrate remains moist even in summer (Sandiford and Barrett 2010; Cross et al. 2019). Given the long period of embryo growth required under optimal thermal and moisture conditions before germination can occur in Cephalotus, the dispersal of seeds into less consistently mesic habitats outside this very narrow niche is unlikely to result in successful recruitment. This may, at least in part, explain why the species typically exhibits such highly localised distribution patterns (Conran 2004; Lowrie 2014; Cross et al. 2018c; 2019), why there is little evidence of successful long-distance dispersal or genetic connectivity between isolated populations (N. Kalfas unpubl. obs., in Cross et al. 2019), and why recruitment in natural populations is observed so infrequently (Cross et al. 2018c; 2019). 
Although the germination success of seeds from all collections on water agar was highest at $15{ }^{\circ} \mathrm{C}$ (Fig. S1), the data showed a degree of both inter-population and inter-seasonal variability in maximum germination success (0.2-0.8). Although neither population nor collection year were significant factors influencing germination success in our analyses, this variability may indicate that seed dormancy depth in Cephalotus is influenced by fine-scale or seasonal variability in the moisture and temperature conditions of the maternal environment as has been observed for other species exhibiting a physiological component to seed dormancy (e.g., Long et al. 2014; Cochrane et al. 2015; Cross et al. 2018a). Seeds that failed to germinate following incubation for 16 weeks on water agar largely remained viable, suggesting that a variable fraction of each collection was more deeply dormant at maturity. Additionally, although both the viability and germinability of seeds (of the AP1 population) declined following drying for seven days at either $50 \%$ or $20 \% \mathrm{RH}$, ca. $30 \%$ of the dried seeds germinated readily when incubated at $20{ }^{\circ} \mathrm{C}$ on water agar after 12 months in storage at -18 or $-80{ }^{\circ} \mathrm{C}$ (Fig. 4). The decline in viability upon drying initially observed may reflect variability in the maturity within the seed populations upon collection, and a greater sensitivity to drying in less mature seeds with higher seed moisture content. Nevertheless, mortality was high, and no germination was observed in seeds stored at $23{ }^{\circ} \mathrm{C}$ for 12 months. This suggests the seeds of Cephalotus may possess only limited capacity for persistence through warm, dry seasonal periods or following dispersal into less mesic habitats. The efficacy of a soil seed bank in conferring population-level resilience to stochastic environmental processes such as drought or fire would depend greatly upon factors such as the capacity for seedling emergence and resilience to the heat from fire at different burial depths (e.g., Auld and Bradstock 1996; Auld and Denham 2006; Cross et al. 2017); the persistence of the achene and its potential role as a seedprotecting structure under field conditions (e.g., Sheldon 1974; Joley et al. 2003; Erickson et al. 2016); the spatial and temporal patterns of seedling emergence in response to recruitmentstimulating events such as flooding (e.g., Carta et al. 2013; Cross et al. 2014; 2015; Metzner et al. 2017); and the longevity of seeds in the soil seed bank under field conditions (Bekker et al. 1998; Long et al. 2014). These should be priority areas for future research focus.

We observed no significant germination response of Cephalotus seeds to the smoke derived chemical $\mathrm{KAR}_{1}$. A germination response to $\mathrm{KAR}_{1}$ is typically observed for many species from fire-prone habitats for which fire plays a part in recruitment from seed (Flematti et al. 2004; Merritt 
et al. 2007a; Baskin and Baskin 2014), including numerous other carnivorous plants that occur sympatrically with, or grow in similarly mesic habitats to Cephalotus (Cross et al. 2013; Cross et al. 2018b). Although Cephalotus appears to be resilient to fire, producing vigorous vegetative regeneration from the subterranean rhizome following summer wildfires (Bradshaw et al. 2018; Cross et al. 2019), it appears unlikely that fire plays a direct role in the stimulation of seed germination. However, it is plausible that Cephalotus possesses an alternative fire-responsive reproductive strategy. It has been hypothesised that insect prey may be present at greater-thanaverage abundance following fire events (e.g., Cross et al. 2017) and the rapid production of insecttrapping pitchers and inflorescences observed for Cephalotus following fire (Conran 2004; Lowrie 2014; Cross et al. 2019) may represent a strategy to exploit prey availability to meet the high energetic demand of regeneration. Enhanced flowering following fire has been previously reported for species from genera such as Xanthorrhoea Sol. ex Sm. (Asphodelaceae), Haemodorum Sm. (Haemodoraceae), and Pyrorchis D.L.Jones \& M.A.Clem. (Orchidaceae) in southwestern Australia (e.g., Lamont and Downes 2011; Miller and Dixon 2014). The late autumn achene release by Cephalotus, coming after the natural timing of mainly summer wildfires (Sandiford and Barrett 2010; Bradshaw et al. 2018), may therefore help to improve the chances of seed dispersal into environments characterised by low competition and high resource availability.

Alteration to natural hydrological regimes has been implicated directly as a causal factor in the decline of multiple Cephalotus populations (Lowrie 2014; Clarke et al. 2018; Cross et al. 2018c; Cross et al. 2019) and climate studies predict that in the near future the southwest of Australia will experience an increasingly warmer climate with markedly reduced rainfall and runoff, as well as higher rates of evaporation (e.g., Silberstein et al. 2012). Under such predicted future climate and land use scenarios for the Southwest region, the recruitment of Cephalotus from seed may become increasingly episodic and unpredictable and, in the long-term, may be largely or completely compromised. Previously the scarcity of information pertaining to the recruitment and reproduction of Cephalotus has limited the knowledge supporting land use decisions, for example regarding fire management in its conservation (Cross et al. 2019). Accordingly, we undertook this assessment of the species' germination biology to help inform future conservation and management initiatives. With recent work indicating that Cephalotus is becoming increasingly impacted by ongoing habitat loss, alteration to natural fire regimes and hydrological changes from 
431 modified land uses (Jennings and Rohr 2011; Lowrie 2014; Clarke et al. 2018; Cross et al. 2019),

432 there is a clear and urgent need for scientifically-guided conservation actions to safeguard the 433 future of this iconic and distinctive species.

435 In the face of predicted ongoing declines in the extent, connectivity and quality of suitable 436 Cephalotus habitat (Cross et al. 2019), we propose that careful fire and hydrological management 437 of habitat remnants will be instrumental to conserving and protecting this ancient and 438 evolutionarily isolated plant lineage. Future studies are needed to examine how far, frequently and 439 successfully the seeds of Cephalotus are dispersed, as well as to determine the capacity for, and 440 resilience of, any in situ seed bank through seed burial and retrieval experiments. There is also an 441 urgent need to quantify the success and dynamics of seed regeneration under field conditions, over 442 spatial and temporal scales and in response to environmental perturbation in the form of fire and 443 low-rainfall periods. This will help determine to what extent Cephalotus is reliant upon recurrent 444 or episodic recruitment from seeds; in the absence of this information, land managers are likely to be poorly equipped to develop meaningful long-term conservation strategies for this species.

\section{Acknowledgements}

The authors thank Lyn Alcock, Maggie Whittle, June Scott, Richard Nieuwhof and Allan Dressler for assistance with fieldwork and seed collections, and Sophie Cross for assistance with figure 451 preparation. This research was supported by the Australian Government through the Australian 452 Research Council Industrial Transformation Training Centre for Mine Site Restoration (Project 453 Number ICI150100041). The views expressed herein are those of the authors and are not 454 necessarily those of the Australian Government or Australian Research Council.

\section{Conflicts of interest}

The authors declare no conflicts of interest.

\section{References}


462

463

464

465

466

467

468

469

470

471

472

473

474

475

476

477

478

479

480

481

482

483

484

485

486

487

488

489

Auld TD, Denham AJ (2006) How much seed remains in the soil after a fire? Plant Ecology 187, $15-24$.

Baker KS, Steadman KJ, Plummer JA, Merritt DJ, Dixon KW (2005) Dormancy release in Australian fire ephemeral seeds during burial increases germination response to smoke water or heat. Seed Science Research 15, 339-348.

Baskin CC, Baskin JM (2004) A classification system for seed dormancy. Seed Science Research 14, 1-16.

Baskin CC, Baskin JM (2014) 'Seeds: Ecology, Biogeography, and Evolution of Dormancy and Germination.' (Academic Press: San Diego).

Bekker RM, Bakker JP, Grandin U, Kalamees R, Milberg P, Poschlod P, Thompson K, Willems JH (1998) Seed size, shape and vertical distribution in the soil: indicators of seed longevity. Functional Ecology 12, 834-842.

Bradshaw SD, Dixon KW, Lambers H, Cross AT, Bailey J, Hopper SD (2018) Understanding the long-term impact of prescribed burning in mediterranean-climate biodiversity hotspots, with a focus on south-western Australia. International Journal of Wildland Fire 27, 643-657.

Carta A, Bedini G, Müller JV, Probert RJ (2013) Comparative seed dormancy and germination of eight annual species of ephemeral wetland vegetation in a Mediterranean climate. Plant Ecology 214, 339-349. 
490 Clarke C, Cross AT, Rice B (2018) Conservation of carnivorous plants. In 'Carnivorous Plants:

491 Physiology, Ecology and Evolution, (Eds L Adamec and A Ellison). (Oxford University Press: 492 London).

493

494 Cochrane A, Yates CJ, Hoyle GL, Nicotra AB (2015) Will among-population variation in seed 495 traits improve the chance of species persistence under climate change? Global Ecology and 496 Biogeography 24, 12-24.

497

498 Conran JG (2004) Cephalotaceae. In 'The families and genera of vascular plants. Volume 6. 499 Flowering plants. Dicotyledons: Celastrales, Oxalidales, Rosales, Cornales, Ericales.' (Ed. K 500 Kubitzki) pp. 65-68. (Springer Verlag: Berlin).

501

502 Conran JG, Denton MD (1996) Germination in the Western Australian Pitcher Plant Cephalotus 503 follicularis and its unusual early seedling development. Western Australian Naturalist 21, 37-42. 504

505 Cronquist A (1981) 'An Integrated System of Classification of Flowering Plants.' (Columbia 506 University Press: New York).

507

508 Cross AT, Barrett MD, Turner SR, Dixon KW, Merritt DJ (2018a) Seed-dormancy depth is 509 partitioned more strongly among habitats than among species in tropical ephemerals. Australian 510 Journal of Botany 66, 230-242.

511

512 Cross AT, Cawthray GR, Merritt DJ, Turner SR, Renton M, Dixon KW (2014) Biogenic ethylene 513 promotes seedling emergence from the sediment seed bank in an ephemeral tropical rock pool 514 habitat. Plant and Soil 380, 73-87. 
516 Cross AT, Davis AR, Fleischmann A, Horner JD, Jürgens A, Merritt DJ, Murza GL, Turner SR

517 (2018b) Reproductive biology and prey-pollinator conflicts. In 'Carnivorous plants: physiology, 518 ecology and evolution.' (Eds L Adamec and A Ellison). (Oxford University Press: London).

519

520

521

522

523

524

525

526

527

528

529

530

531

532

533

534

535

536

537

538

539

540

541

542
Cross AT, Kalfas N, Nunn R, Conran JG (2019) 'Cephalotus, the Albany Pitcher Plant.' (Redfern Natural History Productions: Poole).

Cross AT, Merritt DJ, Turner S, Dixon KW (2013) Seed germination of the carnivorous plant Byblis gigantea (Byblidaceae) is cued by warm stratification and karrikinolide. Botanical Journal of the Linnean Society 173, 143-152.

Cross AT, Paniw M, Ojeda F, Turner SR, Dixon KW, Merritt DJ (2017) Defining the role of fire in alleviating seed dormancy in a rare Mediterranean endemic subshrub. AoB Plants 9, plx036.

Cross AT, Paniw M, Scatigna AV, Kalfas N, Anderson B, Givnish TJ, Fleischmann A (2018c) Systematics and evolution of small carnivorous genera. In 'Carnivorous Plants: Physiology, Ecology and Evolution, (Eds L Adamec and A Ellison).' (Oxford University Press: London).

Cross AT, Turner SR, Renton M, Baskin JM, Dixon KW, Merritt DJ (2015) Seed dormancy and persistent sediment seed banks of ephemeral freshwater rock pools in the Australian monsoon tropics. Annals of Botany 115, 847-859.

Downes KS, Light ME, Posta M, Kohout L, Van Staden J (2013) Comparison of germination responses of Anigozanthos flavidus (Haemodoraceae), Gyrostemon racemiger and Gyrostemon ramulosus (Gyrostemonaceae) to smoke-water and the smoke-derived compounds karrikinolide (KAR1) and glyceronitrile. Annals of Botany 111, 489-497. 
543 Erickson TE, Shackelford N, Dixon KW, Turner SR, Merritt DJ (2016) Overcoming physiological 544 dormancy in seeds of Triodia (Poaceae) to improve restoration in the arid zone. Restoration 545 Ecology 24, S64-S76.

546

547 FAO. 2014. Genebank Standards for Plant Genetic Resources for Food and Agriculture. Rev. ed. 548 Rome.

549

550

Flematti GR, Ghisalberti EL, Dixon KW, Trengove RD (2004) A compound from smoke that 551 promotes seed germination. Science 305, 977.

552

553 Hay FR, Adams J, Manger K, Probert R (2008) The use of non-saturated lithium chloride solutions 554 for experimental control of seed water content. Seed Science and Technology 36, 737-746.

555 556 557

Heibl C, Renner SS (2012) Distribution models and a dated phylogeny for Chilean Oxalis species reveal occupation of new habitats by different lineages, not rapid adaptive radiation. Systematic Biology 61, 823-834.

559

560

Hong, T. D., and R. H. Ellis. 1996. A protocol to determine seed storage behaviour. International 561 Plant Genetic Resources Institute, Rome, Italy.

562

563 Jennings DE, Rohr JR (2011) A review of the conservation threats to carnivorous plants. 564 Biological Conservation 144, 1356 - 1363.

565

566 Joley DB, Maddox DM, Schoenig SE, Mackey BE (2003) Parameters affecting germinability and 567 seed bank dynamics in dimorphic follicles of Centaurea solstitialis in California. Canadian 568 Journal of Botany 81, 993-1007. 
570 Lamont BB, Downes KS (2011) Fire-stimulated flowering among resprouters and geophytes in

571 Australia and South Africa. Plant Ecology 212, 2111-2125.

572

573 Lecoufle M (1990) 'Carnivorous Plants Care and Cultivation.' (Cassell Publishers Limited: 574 London).

575

576 Liyanage GS, Ooi MK (2015) Intra-population level variation in thresholds for physical dormancy-

577 breaking temperature. Annals of Botany 116, 123-131.

578

579 Long RL, Gorecki MJ, Renton M, Scott JK, Colville L, Goggin DE, Commander LE, Westcott

580 DA, Cherry H, Finch-Savage WE (2015) The ecophysiology of seed persistence: a mechanistic 581 view of the journey to germination or demise. Biological Reviews 90(1), 31-59.

582

583 Lowrie A (2014) 'Carnivorous Plants of Australia - Magnum Opus.' (Redfern Natural History 584 Productions: Poole).

585

586 Merritt DJ, Kristiansen M, Flematti GR, Turner SR, Ghisalberti EL, Trengove RD, Dixon KW 587 (2007a) Effects of a butenolide present in smoke on light-mediated germination of Australian 588 Asteraceae. Seed Science Research 16, 29-35.

589

590

591

Merritt DJ, Turner SR, Clarke S, Dixon KW (2007b) Seed dormancy and germination stimulation syndromes for Australian temperate species. Australian Journal of Botany 55, 336-344.

592

593 Metzner K, Gachet S, Rocarpin P, Saatkamp A (2017) Seed bank, seed size and dispersal in 594 moisture gradients of temporary pools in Southern France. Basic and Applied Ecology 21, 13-22. 
596 Miller BP, Dixon KW (2014) Plants and fire in kwongan vegetation. In 'Plant Life on the 597 Sandplains in Southwest Australia: a Global Biodiversity Hotspot.' (Ed. H Lambers) pp. 147-169. 598 (UWA Press: Perth).

599

600 Moore RP (1985) 'Handbook on Tetrazolium Testing.' (International Seed Testing Association: 601 Zurich).

602

603 Pietropaulo J, Pietropaulo P (1986) 'Carnivorous Plants of the World.' (Timber Press: Portland).

604

605 Sandiford EM, Barrett S (2010) Albany Regional Vegetation Survey: extent, type and status. 606 Department of Environment and Conservation, Albany.

607

608 Sheldon JC (1974) The behaviour of seeds in soil: III. The influence of seed morphology and the 609 behaviour of seedlings on the establishment of plants from surface-lying seeds. The Journal of 610 Ecology, 47-66.

611

612 Silberstein RP, Aryal SK, et al. (2012) Climate change and runoff in south-western Australia. 613 Journal of Hydrology 475, 441-455.

614

615 Turner SR, Commander LE, Baskin JM, Baskin CC, Dixon KW (2009) Germination behaviour of 616 Astroloma xerophyllum (Ericaceae), a species with woody indehiscent endocarps. Botanical 617 Journal of the Linnean Society 160, 299-311.

618

619 Yeates D (1992) Immature stages of the apterous fly Badisis ambulans McAlpine (Diptera: 620 Micropezidae). Journal of Natural History 26, 417-424. 


\begin{tabular}{|c|c|c|c|c|c|}
\hline Population & ID & $\begin{array}{l}\text { Collection } \\
\text { date }\end{array}$ & $\begin{array}{l}\text { Post-harvest } \\
\text { handling }\end{array}$ & $\begin{array}{l}\text { Population } \\
\text { location }\end{array}$ & Habitat description \\
\hline Ant Pool & AP2 & January 2006 & $15^{\circ} \mathrm{C}, 15 \% \mathrm{RH}$ & $116^{\circ} 30^{\prime} \mathrm{E}$ & $\begin{array}{l}\text { Homalospermum firmum/Callistemon glaucus } \\
\text { peat thicket; } \\
\text { C. follicularis occurring with Drosera } \\
\text { hamiltonii and Lycopodiella serpentina in dense } \\
\text { seepage sedgeland of Leptocarpus tenax, } \\
\text { Gymnoschoenus anceps, Evandra aristata, } \\
\text { Schoenus multiglumis and S. efoliatus growing } \\
\text { under Callistemon glaucus and } \\
\text { Homalospermum firmum. }\end{array}$ \\
\hline Gull Rock & GR & January 2017 & $\begin{array}{l}\text { Hermetically } \\
\text { sealed }\end{array}$ & $\begin{array}{l}34^{\circ} 59^{\prime} \mathrm{S} \\
117^{\circ} 59^{\prime} \mathrm{E}\end{array}$ & $\begin{array}{l}\text { Homalospermum firmum/Callistemon glaucus } \\
\text { peat thicket; } \\
\text { C. follicularis occurring with Lycopodiella } \\
\text { serpentina in open seepage sedgeland of } \\
\text { Leptocarpus tenax, Gymnoschoenus anceps, } \\
\text { Evandra aristata, Schoenus multiglumis and S. } \\
\text { efoliatus with scattered Callistemon glaucus and } \\
\text { Homalospermum firmum. }\end{array}$ \\
\hline Marbelup & MA & January 2018 & $\begin{array}{l}\text { Hermetically } \\
\text { sealed }\end{array}$ & $\begin{array}{l}34^{\circ} 59^{\prime} S \\
117^{\circ} 43^{\prime} E\end{array}$ & $\begin{array}{l}\text { Homalospermum firmum/Callistemon glaucus } \\
\text { peat thicket; } \\
\text { C. follicularis occurring in dense seepage } \\
\text { sedgeland of Leptocarpus tenax, } \\
\text { Gymnoschoenus anceps, Evandra aristata, } \\
\text { Schoenus multiglumis and S. efoliatus with } \\
\text { Homalospermum firmum and scattered } \\
\text { Callistemon glaucus. }\end{array}$ \\
\hline
\end{tabular}




\section{Figure captions}

643

644

645

646

647

648

649

650

651

652

653

654

655

656

657

658

659

660

661

662

663

664

665

666

667

668

669

670

671

Figure 1. Localities in the southwest of Western Australia from which Cephalotus follicularis seeds were collected for this study (A), and monthly minimum (bold) and maximum temperature and rainfall ranges for the Albany region in which this species occurs (B).

Figure 2. Seed germination morphology in Cephalotus follicularis. The diaspore comprises an achene (A) containing a single indehiscent seed (B) with a linear embryo (C). Germination is phanerocotylar, with cotyledons (and seed coat remnant) emerging from the persistent achene ( $\mathrm{D}_{\mathrm{I}^{-}}$ $\mathrm{D}_{\text {III }}$. The fully-expanded cotyledons are obovate $\left(\mathrm{D}_{\mathrm{II}}\right)$, and the first leaves are alternate and noncarnivorous ( $\left.D_{\text {IV }}\right)$. Extracted seeds become slightly ovoid in shape once imbibed for 23 hours $\left(E_{I}\right)$, then, after several weeks incubation, they are observed to swell significantly with the papery testa beginning to crack ( $\left.\mathrm{E}_{\mathrm{II}}\right)$ several days prior to hypocotyl extension (EIII). Shortly thereafter a nonvascularized parenchymatous and fusiform hypocotyl extension develops and emerges from the seeds (Fig. $2 \mathrm{E}_{\mathrm{III}}-\mathrm{EV}_{\mathrm{V}}$ ) before the emergence of the cotyledons (Fig. $2 \mathrm{E}_{\mathrm{VI}}$ ) followed lastly by the radicle (Fig. 2E $\left.\mathrm{E}_{\mathrm{VII}}-\mathrm{E}_{\mathrm{VIII}}\right)$. Scale bars $=1 \mathrm{~mm}$.

Figure 3. Germination success (mean probability with exact binomial 95\% confidence limits) of freshly collected Cephalotus follicularis achenes and seeds extracted from achenes incubated on $0.7 \%$ (w/v) water agar (control), water agar containing $\mathrm{GA}_{3}$ and water agar containing $\mathrm{KAR}_{1}$ at constant $5,10,15,20$ and $25^{\circ} \mathrm{C}$ for 16 weeks with a 12-h photoperiod. Data are pooled germination probabilities for all populations. Annotated lettering represents the results of conditional pairwise comparison tests (contrasts within each treatment). Values followed by the same or no letters are not significantly different among temperatures (at $P \leq 0.05$ ).

Figure 4. Germination success (mean probability with exact binomial 95\% confidence limits) of freshly collected (AP1) Cephalotus follicularis seeds, seeds equilibrated at $50 \%$ or $20 \%$ relative humidity for seven days, and seeds equilibrated at $50 \%$ or $20 \%$ relative humidity for seven days then stored for 12 months at $23,-18$ or $-80{ }^{\circ} \mathrm{C}$, incubated on $0.7 \%(w / v)$ water agar and water agar containing $\mathrm{GA}_{3}$ at $15{ }^{\circ} \mathrm{C}$ for 16 weeks in constant darkness. Annotated lettering represents the 
672 results of conditional pairwise comparison tests (contrasts within each treatment). Values followed 673 by the same or no letters are not significantly different for each estimate (at $P \leq 0.05$ ).

674

675 Figure 5. Distribution of seed length, embryo length and E:S ratio of fresh seeds (FS) and pre676 germinating seeds (PG) of Cephalotus follicularis from MA incubated on 0.7\% (w/v) water agar 677 at $20^{\circ} \mathrm{C}$ for 16 weeks on a 12 -h photoperiod.

678

679 